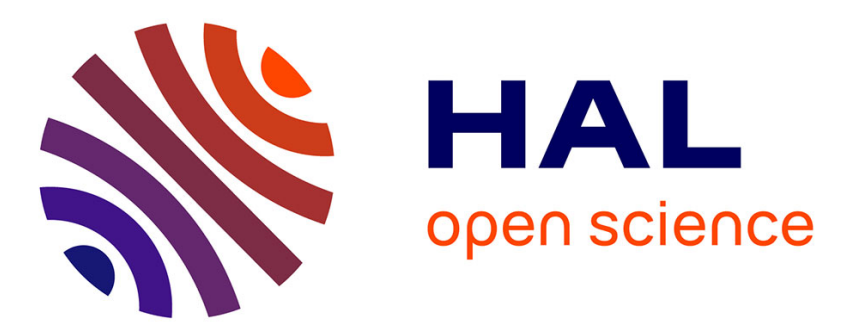

\title{
Impact of direct solar irradiance on heat transfer behind an open-jointed ventilated cladding: Experimental and numerical investigations
}

Matthieu Labat, Monika Woloszyn, Géraldine Garnier, Gilles Rusaouen, Jean Jacques Roux

\section{To cite this version:}

Matthieu Labat, Monika Woloszyn, Géraldine Garnier, Gilles Rusaouen, Jean Jacques Roux. Impact of direct solar irradiance on heat transfer behind an open-jointed ventilated cladding: Experimental and numerical investigations. Solar Energy, 2012, 86 (9), pp.2549-2560. 10.1016/j.solener.2012.05.030 . hal-02086904

\section{HAL Id: hal-02086904 https://hal.science/hal-02086904}

Submitted on 3 Apr 2019

HAL is a multi-disciplinary open access archive for the deposit and dissemination of scientific research documents, whether they are published or not. The documents may come from teaching and research institutions in France or abroad, or from public or private research centers.
L'archive ouverte pluridisciplinaire HAL, est destinée au dépôt et à la diffusion de documents scientifiques de niveau recherche, publiés ou non, émanant des établissements d'enseignement et de recherche français ou étrangers, des laboratoires publics ou privés. 


\title{
Impact of direct solar irradiance on heat transfer behind an open- jointed ventilated cladding: experimental and numerical investigations
}

\author{
Matthieu Labat ${ }^{1,2}$ \\ Monika Woloszyn ${ }^{3}$ \\ Geraldine Garnier $^{2}$ \\ Gilles Rusaouen $^{1}$ \\ Jean Jacques Roux ${ }^{1}$ \\ ${ }^{1}$ CNRS : UMR5008 - INSA - Institut National des Sciences Appliquées - Université Claude Bernard \\ - Lyon I, France \\ ${ }^{2}$ CSTB - Centre Scientifique et Technique du Bâtiment \\ 24 rue Joseph Fourier, 38400 Saint Martin d'Hères \\ ${ }^{3}$ Laboratoire Optimisation de la Conception et Ingénierie de l'Environnement (LOCIE), CNRS- \\ UMR5271, Université de Savoie, Campus Scientifique, Savoie Technolac, 73376 Le Bourget-Du-Lac \\ cedex, France \\ Corresponding author: \\ Matthieu Labat \\ INSA de Lyon, Bât. Sadi Carnot \\ 20, Av. A. EINSTEIN 69621 Villeurbanne Cedex FRANCE \\ e-mail matthieu.labat@insa-lyon.fr \\ tel : 33472437420 \\ fax : 33472438811
}

KEYWORDS: Outdoor exposure, temperature distribution, airflow measurements, CFD simulation, solar irradiance, ventilated cladding

\section{SUMMARY:}

This paper is based on the study of an experimental wooden-framed house, equipped with a ventilated cladding, located in France. The focus is on investigating the heat transfer taking place in the ventilated air gap behind the cladding and on estimating their impact on heat transfer in the insulated part of the walls.

Preliminary CFD simulation made it possible to describe the airflow in the ventilated air gap when buoyancy was acting as the main driving force. It was found that the airflow velocity could reach $0.8 \mathrm{~m} \cdot \mathrm{s}^{-1}$, when exposed to $570 \mathrm{~W} \cdot \mathrm{m}^{-2}$ solar irradiance. This was verified experimentally. A correlation to assess airflow rate in the air gap behind the cladding has been developed based on temperature differences and on experimental conclusions. The correlation is adapted to energy performance simulation and efficiently represents the average cavity airflow at different height for various irradiance and temperature conditions. 


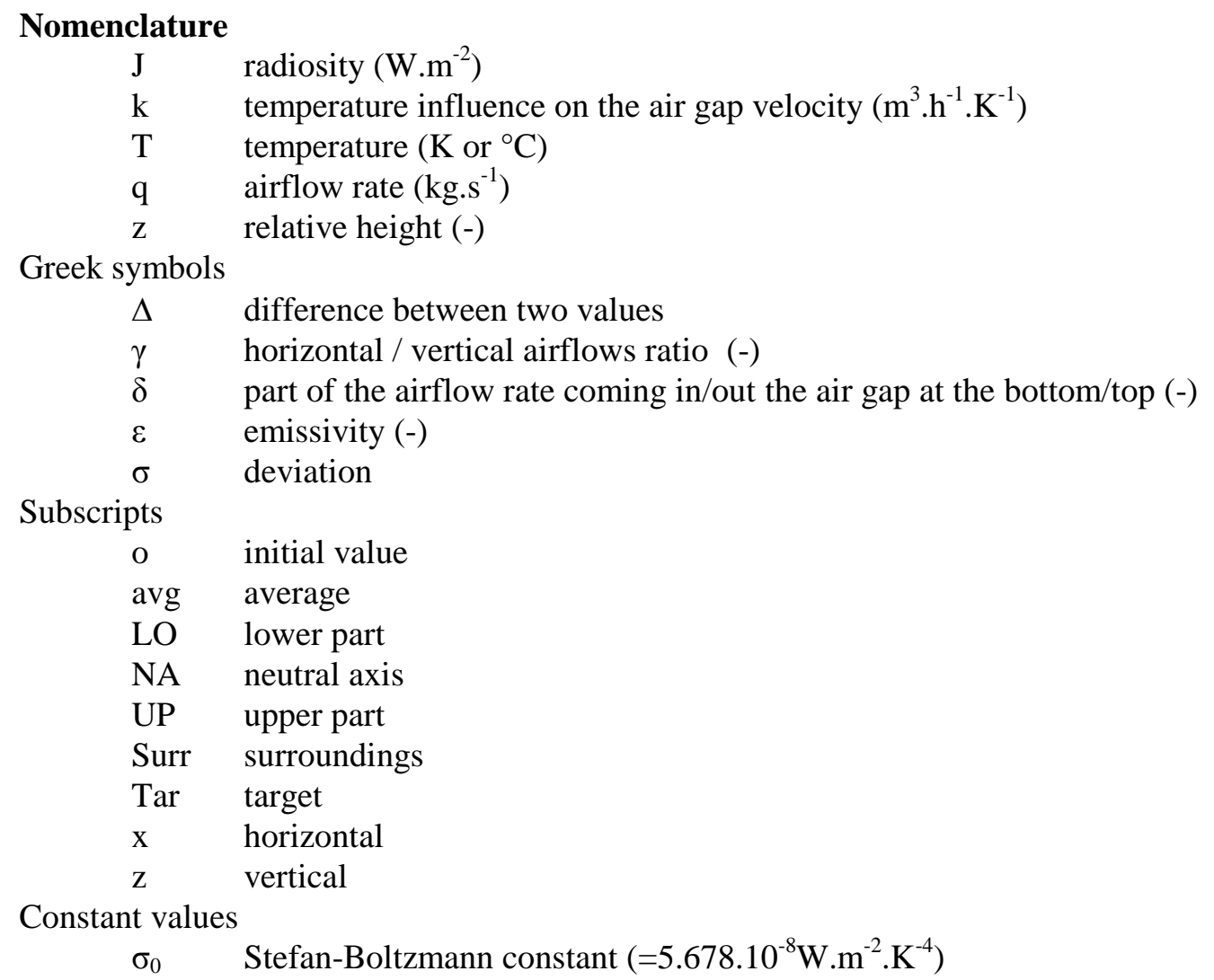

\section{Introduction}

Numerical simulation tools have become widespread in building design to predict energy efficiency and to compare wall configuration sustainability. In particular, coupled heat and vapor transfers are of great interest, as underlined by Annex 41 of the International Energy Agency, ECBCS program (Holm 2009). In order to gain confidence in simulation tools however, validation examples are needed, with both laboratory and field tests. Field tests are interesting as they allow us to consider the influence of real, complex weather conditions on heat and moisture transfers. However, such conditions also make it more difficult to define the boundary limits.

In the field of lightweight structures, ventilated cladding is often used to protect the outdoor facing against rough weather conditions such as wind driven rain. However, complex transfers still occur in such structures and need to be defined. Complete studies have been dedicated to such building elements (Nore 2009, Gudum 2003): in order to estimate the airflow rate within the ventilated gap, both prefer the use of empirical formula drawn from wind speed measurements, but these are specific to the studied buildings. Otherwise, Olof Hägerstedt and Harderup (2011) suggested using a $0.3 \mathrm{~m} . \mathrm{s}^{-1}$ constant velocity in the ventilated air gap, as did Piot (2009) with a value of $0.1 \mathrm{~m} . \mathrm{s}^{-1}$. Sanjuan et al. (2011) studied the specific case of an open joint ventilated façade in detail, but do not give a general formula.

Field test experiments are often carried out on north facing walls so that solar irradiance has little effect. This makes it easier to study heat and vapor transfers (Zerihun et al. 2011). Gudum (2003) also 
studied a north facing wall but noted that buoyancy driven air flow should be taken into account. Despite being among the first to take thermal buoyancy into consideration, by indicating that it could counteract wind effect, Nore (2009) did not include it in the final air rate correlation. Such a limitation also makes it impossible to consider solar related hygrothermal phenomena such as "sundriven vapor" (Piot et al. 2011).

On the other hand, many studies can be found in literature on the subject of buoyancy driven air flows, when looking at double skin façades (Hensen et al. 2002) or Building Integrated Photovoltaics (BIPV) (Gan 2009) for example. However, the geometries studied are generally very different from that of ventilated cladding and air flows are strongly influenced by channel dimensions (Yilmaz and Fraser 2007), heating sources (Fossa et al. 2008) and even additional air flows through open joints (Sanjuan et al. 2011). As a consequence, it is difficult to compare such results to the specific case of ventilated cladding.

It was anticipated that a better assessment of the air flow within the ventilated gap would improve data analysis and enable us to enhance numerical models. Moreover, preliminary investigation showed that one-dimensional modelling of an insulated wall with ventilated cladding was not able to represent correctly energy transfer while direct solar irradiance was occurring (Piot, 2009). For these reasons, the present work focuses on heat transfer taking place within walls equipped with ventilated cladding under direct solar irradiance. An east facing wall was investigated during the summer, as solar irradiation is then at its highest and buoyancy is thought to be the main driving force. An existing wooden-framed experimental house was chosen as a support and is briefly described in the first part of this paper. Next, a preliminary study, conducted in order to gain knowledge of the air gap behaviour and to enable us to set up the instrumentation effectively, is presented. Then the measurements taken in August 2011 are described and analysed. The last part of the paper introduces a new model able to representing the airflows, validated against the measurements.

\section{Experimental set up}

\subsection{General description}

The experimental house is built in Grenoble, France (latitude: $45.2^{\circ} \mathrm{E}$, longitude: $5.77^{\circ} \mathrm{N}$ ) and is exposed to a natural climate. It consists of a single room building, the dimensions of which were designed to be representative of a living room $\left(4.56 \times 4.55 \times 2.41 \mathrm{~m}^{3}\right.$ interior dimensions), designed and instrumented in order to gain knowledge of whole building heat-air-moisture behaviour (Piot et al. 2011).

The height of the ceiling is slightly lower than in usual constructions as the insulation of the ceiling has been increased on the interior side to enable the study to focus on transfer within the vertical walls. The structure is made of vertical spruce studs (section: $0.07 \times 0.165 \mathrm{~m}$ ), positioned every $0.60 \mathrm{~m}$. The roof is a typical French tiled roof, with two $30^{\circ}$ slopes, facing north and south. The floor has been elevated to $0.60 \mathrm{~m}$ above the ground, in order to simplify the boundary conditions for the numerical models. The door, which is the only opening into the test house, is located in the middle of the northern side. The composition of the vertical walls, during the experimental period considered here, is as follows: gypsum boards on the interior, a vapor barrier, cellulose wadding as insulation material between the spruce studs, particle boards on the exterior, a rain-screen, a $0.027 \mathrm{~m}$ wide ventilated air gap and the wooden cladding (see Fig. 1). 


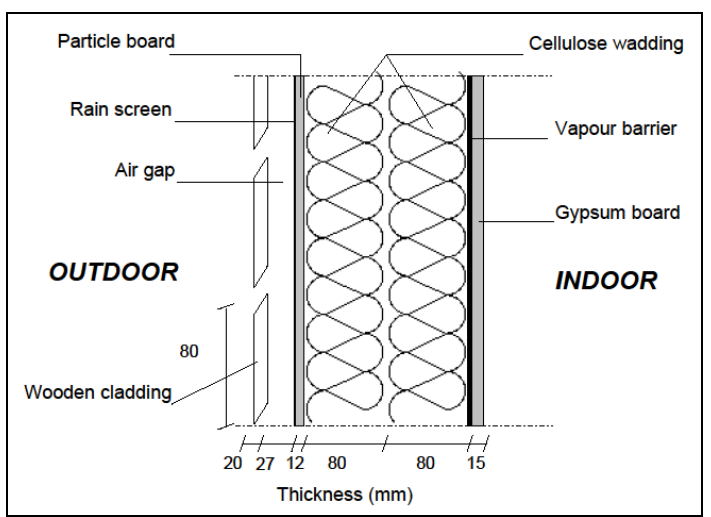

Fig. 1: Scheme of a vertical wall section

\subsection{Ventilated cladding}

The cladding is open-jointed: it is made up of boards with typical dimensions $5 * 0.08 * 0.02 \mathrm{~m}\left(\mathrm{~L}^{*} \mathrm{H} * \mathrm{l}\right)$ which are vertically spaced to create a $0.008 \mathrm{~m}$ high air gap between two adjacent boards. As the gaps are small (less than $10 \%$ of the surface) and slanted, they are not visible on the general photography presented in Fig. 2. The bottom of the ventilated air gap is terminated by a metal plate with large openings drilled on more than $60 \%$ of its surface, so that air can move freely across it. The air gap between the board at the very top and the roof is only $0.008 \mathrm{~m}$ high, as between two boards. As the openings are regularly spaced all along the height and as their dimensions are identical, wind pressure should be similar throughout and wind should influence the air gap behaviour moderately.

Vertical cleats located behind the cladding make it possible to maintain six boards in a row. The vertical cleats are spaced every $0.6 \mathrm{~m}$ and are continuous from the bottom to the top of the cladding, dividing the air gap into independent regular cavities of $0.60 * 0.027 * 3.8 \mathrm{~m}^{3}$. Moreover, there is no link between the air gaps located at different walls. Therefore the main air flow in the air gap can be assumed vertical.

Because of the roof slope on the eastern side, the number of superimposed boards depends on the position considered. The roof overhang is very short $(<0.2 \mathrm{~m})$ over the whole façade and should influence the air pattern only for at the highest altitudes. As this study aims at drawing general results, it was necessary to avoid side effects. As a consequence, our investigation will focus on the first forty four boards and on the air gap part delimited by two consecutive studs, of which one is located at middle length. The boards are numbered from the bottom to the top and some of them are identified in Fig. 2. 


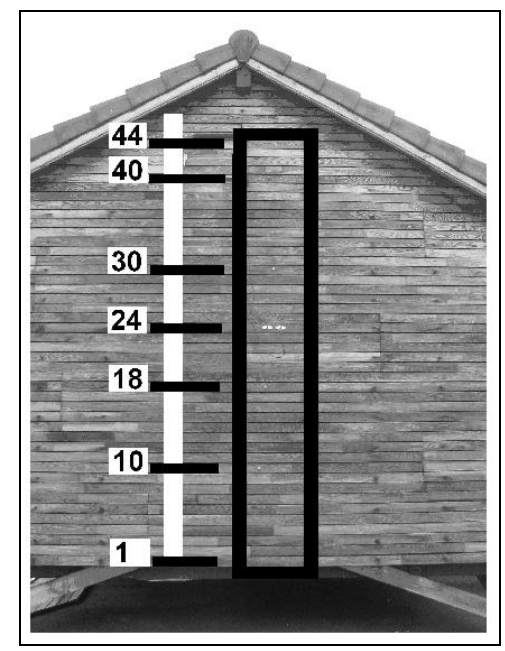

Fig. 2: Picture of the eastern side of the experimental house identifying the investigated part (framed area) and board numbers.

Temperature and relative humidity sensors are located at different depths inside the wall as well as in the indoor air volume. However, no detailed measurements of outdoor surface temperature and no air velocity measurements were achieved and these will need to be investigated now.

\section{Using simulations to gain knowledge of air flow behaviour}

Complex phenomena are bound to occur within the ventilated air gap under direct solar radiation because of the numerous openings. This part of the study aims at investigating general air flow behaviour when the main driving force is buoyancy. Computational Fluid Dynamics (CFD) software Star CCM was selected to compute the steady airflow and heat transfer around the cladding when strong solar irradiance is occurring. This was based upon weather conditions and on-site measurements recorded in August 2010 as boundary conditions.

\subsection{Methodology}

As already mentioned, the width of the air cavity is less than $5 \%$ of the length, the openings are equally distributed on the length, and the solar irradiance was found to be a very influencing boundary condition. The impact of wind, considered negligible, was not represented. Therefore, a 2D geometry was simulated. Such choices were also made by Gan (2009) in order to model the air flow around BIPV in rough thermal conditions.

Both the solid and fluid domains are defined as illustrated in Fig. 3 and include: the insulated part of the eastern wall, the fluid located in the attic and the roof which covers it, the cladding (made up of 44 regularly spaced boards), and finally, a fluid domain inside and outside the ventilated air gap. The latter domain is defined as going down to the ground ( $0.6 \mathrm{~m}$ below the first board), $0.5 \mathrm{~m}$ away from the cladding in a horizontal direction, and $0.6 \mathrm{~m}$ above the highest board. 


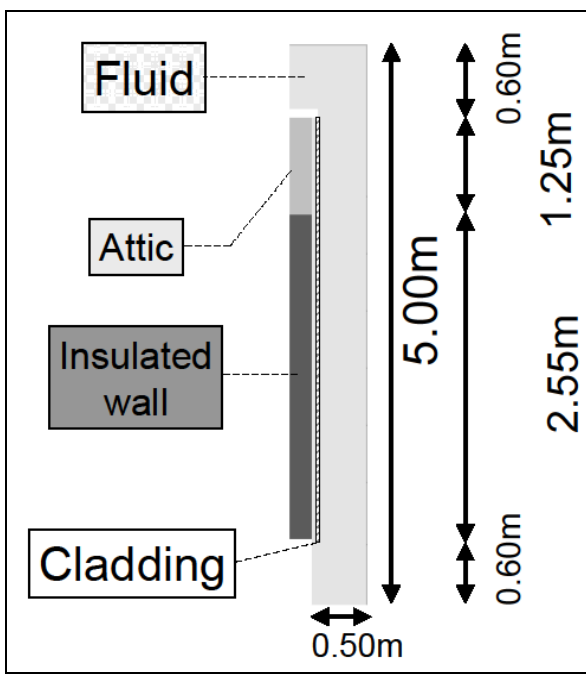

Fig. 3: Scheme of the solid and fluid regions with main vertical dimensions

Mesh refinement has been set to a sharp level in the ventilated air gap and close to the boards $(1 \mathrm{~mm})$, as suggested by Sanjuan et al. (2011), growing quickly to $2.5 \mathrm{~mm}$ inside the solid regions and in the earliest fluid regions (see Fig. 4). It can even reach $5 \mathrm{~mm}$ for the later fluid regions and in the insulated wall. As a consequence, a single board contains 1500 cells and the fluid domain is meshed with more than 140000 cells in the whole ventilated air gap. Finally, the mesh is constructed with using hexahedral cells.

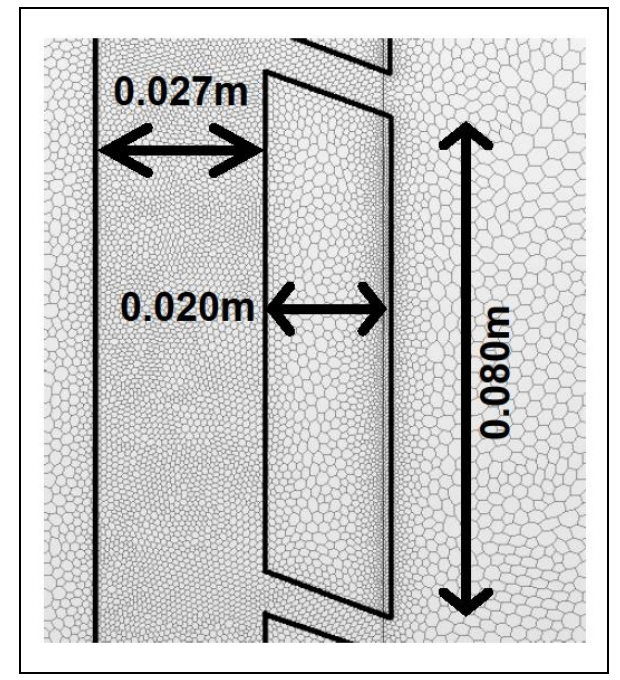

Fig. 4: Mesh refinement in the ventilated air gap and around a single board. Bold lines represent the solid / fluid interfaces.

Three types of boundary conditions were used: constant temperature, zero pressure and adiabatic walls. The fluid domain limits were set at air temperature $\left(23^{\circ} \mathrm{C}\right)$ and using the same gauge pressure, so that the flow would result from thermal buoyancy only (Gan 2009). Temperature measurements on indoor facing walls $\left(23^{\circ} \mathrm{C}\right)$ and in the attic $\left(32^{\circ} \mathrm{C}\right)$ were used as boundary conditions. Finally, the roof, the floor and the ceiling of the test house and the ground were also set as adiabatic. 


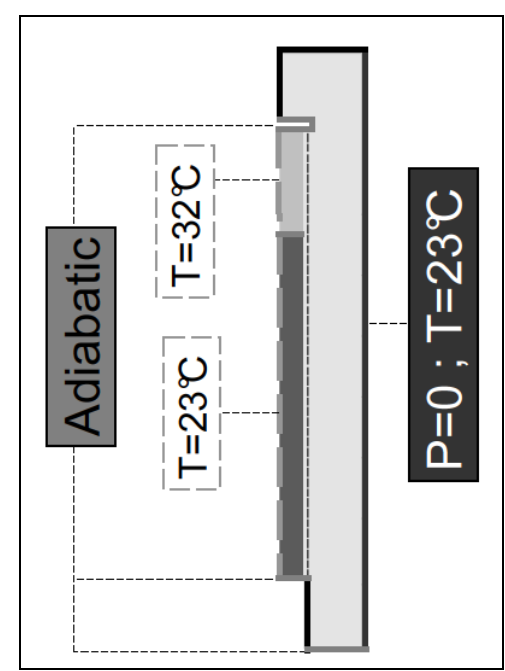

Fig. 5: Boundary conditions applied to domain limits

The RANS k- $\varepsilon$ realisable turbulence model was used in order to model the turbulent air flow and heat transfers, as in Nore (2010) and Sanjuan (2011). In order to represent absorbed solar irradiance, energy volume sources were added to each board, $1 \mathrm{~mm}$ away from the interface with the outdoor air. The simulation was performed for a single steady state case, when energy sources amplitude was set to $340 \mathrm{~W} \cdot \mathrm{m}^{-2}$ so that they modelled the average absorbed heat, corresponding to solar irradiance measured on site between $7 \mathrm{~h}$ and $9 \mathrm{~h}$ (True Solar Time). Irradiative transfer was also modelled in the ventilated air gap. The thermal properties of the cladding boards were measured under optimal conditions and are presented in Table 1 below.

Table 1: Cladding thermal properties

\begin{tabular}{llllll}
\hline Property & Conductivity & Density & Capacity & Emissivity & Solar absorptance \\
\hline Unit & $\mathrm{W} \cdot \mathrm{m}^{-1} \cdot \mathrm{K}^{-1}$ & $\mathrm{Kg} \cdot \mathrm{m}^{-3}$ & $\mathrm{~J} \cdot \mathrm{kg}^{-1} \cdot \mathrm{K}^{-1}$ & - & - \\
\hline Value & 0.13 & 378 & 1500 & 0.86 & 0.6 \\
\hline
\end{tabular}

\subsection{Results}

Stream lines plotted in Fig. 6 show the general air flow pattern. As the ventilated air gap is thin and spread over a considerable height, only the bottom and upper parts have been represented. The black areas correspond to solid domains (insulated wall and cladding). The fluid in the attic has not been represented, even though it was computed. 


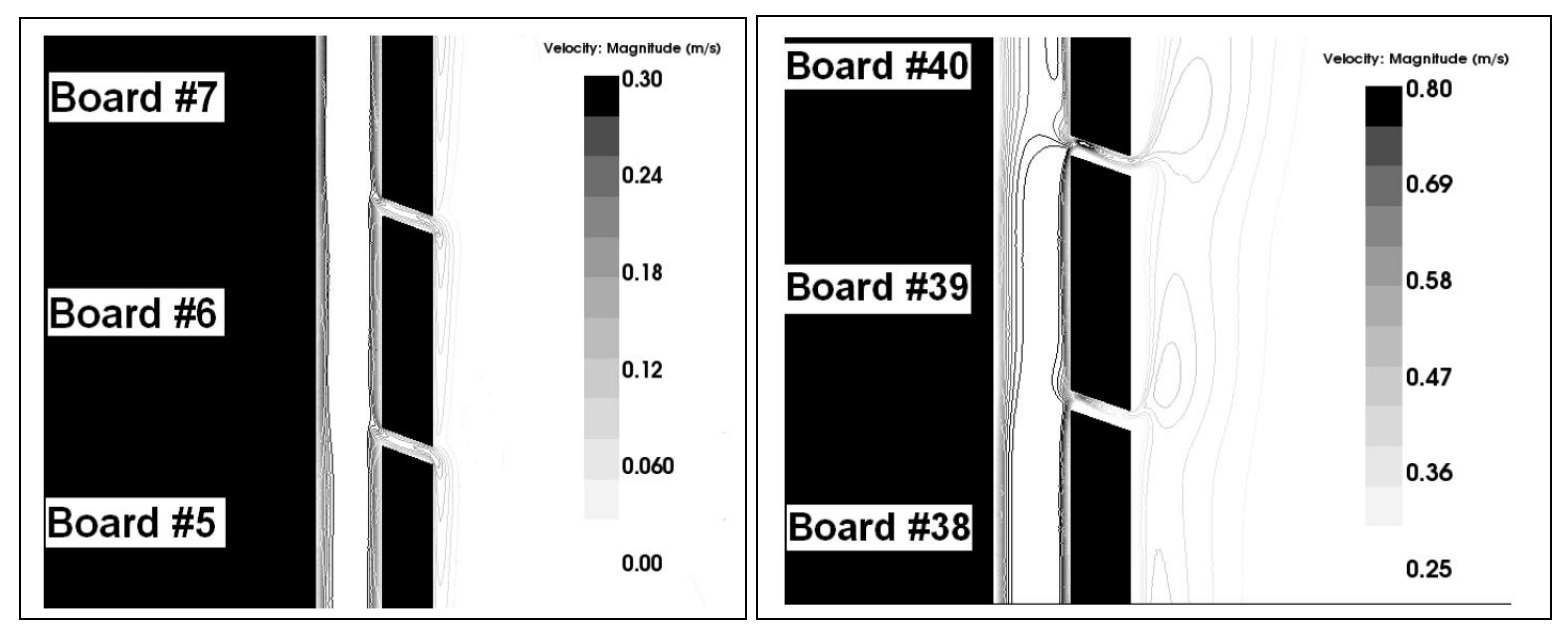

Fig. 6: Air flow patterns at the bottom of the cladding (left) and at the top (right).

In order to study the air flow in great detail, the vertical air velocity has been plotted against the distance from the insulated wall (d), in Fig. 7 for five relative heights (z), which correspond to boards $\# 10, \# 18, \# 24, \# 30$ and \#35 as presented in Fig. 2.

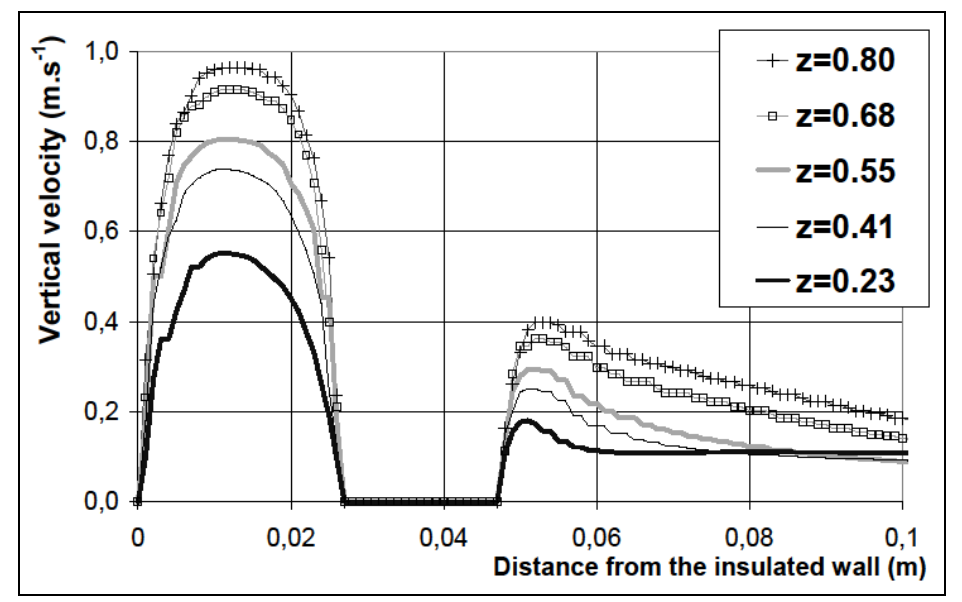

Fig. 7: Vertical air velocity profiles at different relative heights

Two different air flows have developed: one in the ventilated air gap $(0<\mathrm{d}<0.027 \mathrm{~m})$ and one on the outdoor side of the cladding ( $>0.047 \mathrm{~m})$. This second air flow, which is of less interest here, has developed up to $0.35 \mathrm{~m}$ away from the cladding (the fluid domain limit is set at $0.45 \mathrm{~m}$ away from the cladding).

Concerning the flow in the ventilated air gap itself, it emerges that the average vertical air velocity varies greatly according to the height. For example, it is doubled between relative heights $\mathrm{z}=0.23$ and $\mathrm{z}=0.80$. As the simulated air gap cross section remains the same over the entire height, this reveals that the air flow rate is not constant along the entire height, meaning that additional air flows are regularly coming in by means of the numerous openings. This can be verified by looking at the average horizontal air velocities which are taking place between boards at $d=0.037 \mathrm{~m}$ (see Fig. 8). 


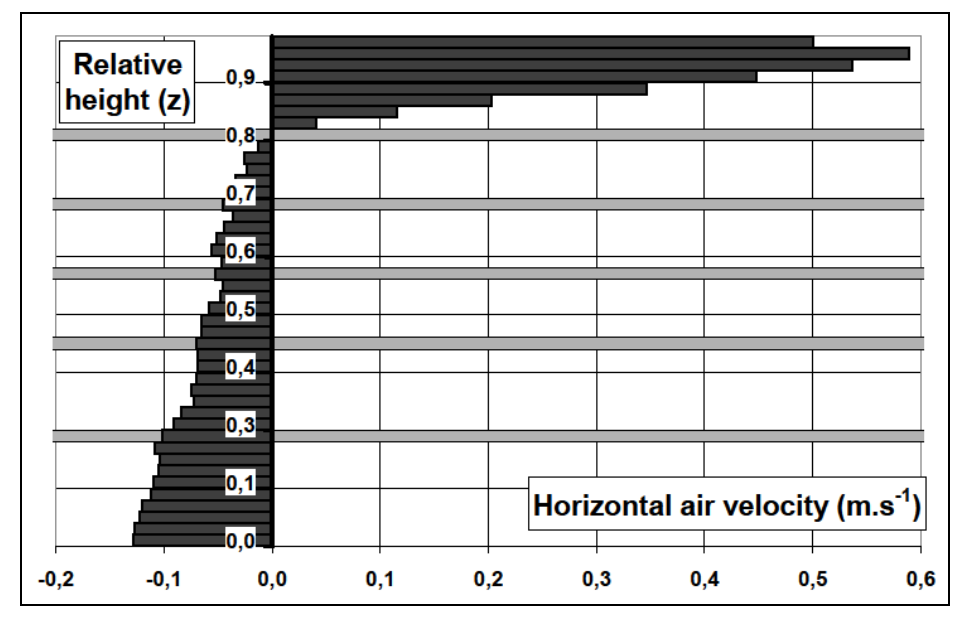

Fig. 8: Horizontal air velocities between boards along the entire height. Coloured strips correspond to the relative heights presented in Fig. 7

Indeed, a negative $0.1 \mathrm{~m} . \mathrm{s}^{-1}$ horizontal air speed has been computed between the first ten boards. This progressively decreases to become positive when the relative height is greater than $\mathrm{z}=0.8$, meaning that the air flow is coming out of the ventilated air gap between the top eight boards.

The main stream, occurring inside the ventilated air gap, is regularly alimented by additional secondary flows. Their relative contribution to the main stream decreases with height, limiting their impact and leading to an average $0.8 \mathrm{~m} \cdot \mathrm{s}^{-1}$ velocity at a relative height of $\mathrm{z}=0.8$. Sanjuan et al. (2011) reached similar conclusions when studying the air pattern around a four slab cladding, yet the horizontal distribution was found to be symmetrical so the velocity was the highest at $\mathrm{z}=0.5$. The nonrectangular shape of the slabs used here could explain such a difference.

The profile shape suggests that above $\mathrm{z}=0.2$, the main stream direction is hardly affected by the secondary air flow rates and is similar to channel flows. In optimal conditions, Yilmaz (2009) also measured a $0.8 \mathrm{~m} \cdot \mathrm{s}^{-1}$ air velocity in a vertical channel with asymmetrical heating. However, the studied channel was not open-jointed and its width was ten times greater.

As the cladding geometry, which is of interest here, is rather specific, it does not seem to be directly comparable to the general results from literature. It was therefore decided that carrying out an on site experimental campaign would bring complementary information to the CFD results. The test house instrumentation was extended so that measurements could be taken simultaneously on the outdoor facing of the cladding, inside the ventilated air gap and on the rain-screen.

\section{Instrumentation}

\subsection{Infrared measurements on the outdoor facing of the cladding}

Achieving surface temperature measurements under direct solar irradiance is not easy, as most sensors are sensitive to solar irradiance. An interesting alternative consists in using an infrared camera (Bazilian et al. 2002) as it avoids this drawback while allowing the measurement of temperatures over an entire surface rather than at punctual locations. In order to do so, a FLIR A-320 camera was set up in front of the eastern wall. The camera had a resolution of 320x240 pixels and worked in the spectral range from 7.5 to $13.0 \mu \mathrm{m}$ (it does not record solar shortwave irradiance). 
As temperatures are computed from infrared radiation (IR) measurements (Korukçu et al. 2009), radiation equations must be considered. According to Kirchhoff's law, real bodies partially reflect infrared radiation emitted by the surrounding surfaces at a temperature of $\mathrm{T}_{\text {Surr }}$. As a result, the camera will receive primary radiation emitted and the reflected radiation incident from surroundings by the target, so the radiosity $\mathrm{J}$ may be written as equation (1) (Buchlin 2010).

$$
J=\varepsilon \cdot \sigma_{0} \cdot T_{\text {Tar }}^{4}+(1-\varepsilon) \cdot \sigma_{0} \cdot T_{\text {Surr }}^{4}
$$

Therefore, two parameters are needed in order to assess accurate measurements: the target's infrared emissivity and the temperature of the surroundings.

The target's emissivity is compared to a reference one, coming from a well-known reference body, adjacent to the target (Bazilian et al. 2002). In this case, the reference body is a strip of black tape with excellent conductive contact, which is placed on the wooden cladding. Its emissivity was precisely measured in a laboratory $(0.88 \pm 0.01)$. It was found that the cladding emissivity varied between 0.8 and 0.88 (the average value is 0.86 , see Table 1). Measurements at punctual locations were also achieved in mint conditions and were found to be in good agreement.

In order to measure the irradiative flux emitted by the surrounding surfaces, a highly reflective and diffusive surface was needed (Dactu et al. 2005). In this work, five previously crumpled sheets of aluminium foil were applied at different heights to assess the vertical distribution of the irradiative flux emitted by the surrounding surfaces. Experimental results showed that $\mathrm{T}_{\text {Surr }}$ was time and location-dependent. As $\mathrm{T}_{\text {Surr }}$ has a direct impact on the surface temperature measurements, it was assessed independently for the five locations and as a function of time.

Uncertainty calculation showed that this technique leads to $\pm 1^{\circ} \mathrm{C}$ accurate measurements, which is of noticeably good quality in comparison with similar studies (Dactu et al. 2005, Bazilian et al. 2002, Korukçu et al. 2009).

As the device had to be set up outdoors and needed to be connected to a computer, measurements were taken over time limited periods, from $4 \mathrm{~h}$ to $14 \mathrm{~h}$. Indeed, there was no more direct solar irradiance on the eastern wall after $12 \mathrm{~h}$ and preliminary measurements showed that the cladding's temperature was little affected by outdoor conditions in the late afternoon.

\subsection{Measurements in the ventilated air gap}

Measurements within the ventilated air gap were obtained by means of two hot wire anemometers which are sensitive to air movements ranging from 0.06 to $1.0 \mathrm{~m} . \mathrm{s}^{-1}$. This device also records temperatures ranging from -40 to $+120^{\circ} \mathrm{C}$. The measuring element was protected against collisions and was therefore not sensitive to flow direction. Finally, measurements were taken every second, averaged over 15 seconds and recorded every minute.

As the preliminary CFD results showed that the air gap velocity was not likely to be constant along the entire height, five locations were selected to investigate air speed measurements. As only two sensors were available at the same time, one was dedicated to a specific position, referred to as \#V3 in Table 2 below, whereas the second one was regularly moved to obtain measurements at the four remaining locations.

Table 2: Reference numbers for hot wire anemomter locations with associated heights and board numbers

\begin{tabular}{llllll}
\hline Reference & \#V1 & \#V2 & \#V3* & \#V4 & \#V5 \\
\hline Relative height z & 0.23 & 0.41 & 0.55 & 0.68 & 0.91 \\
\hline
\end{tabular}




\begin{tabular}{lccccc}
\hline Board Number & 10 & 18 & 24 & 30 & 40 \\
\hline * Reference position - one sensor has always remained at this location & & & \\
\hline
\end{tabular}

Finally, air speed measurement locations were selected in order to avoid proximity with elements of the framework in the air gap, so the location in the width of air gap therefore varied depending on the height considered.

Eight T-type thermocouples were also stuck onto the rain-screen using thermal glue and were regularly placed in the ventilated air gap as shown in Table 3. Measurements were again recorded every minute.

Table 3: Reference numbers for thermocouple locations with associated heights and board numbers

\begin{tabular}{lllllllll}
\hline Reference & \#T1 & \#T2 & \#T3 & \#T4 & \#T5 & \#T6 & \#T7 & \#T8 \\
\hline Relative height z & 0.02 & 0.14 & 0.25 & 0.37 & 0.5 & 0.64 & 0.75 & 0.86 \\
\hline Board Number & 1 & 6 & 11 & 16 & 22 & 28 & 33 & 38 \\
\hline
\end{tabular}

\subsection{Weather conditions}

An on-site weather station recorded the climatic conditions, including wind speed and direction measured at $8 \mathrm{~m}$ above the ground. Diffuse and direct solar irradiance were also measured. As our focus was mainly on heat transfer occurring under strong solar irradiation, the experimental campaign took place in August 2011 when the weather conditions were bound to be the most favourable. This can be checked by looking at the air temperature and solar irradiance measured during this period (see Fig. 9); maximum air temperature is always greater than $20^{\circ} \mathrm{C}$ and can reach $34^{\circ} \mathrm{C}$ while solar irradiance is frequently higher than $600 \mathrm{~W} \cdot \mathrm{m}^{-2}$ on cladding, in peak values.
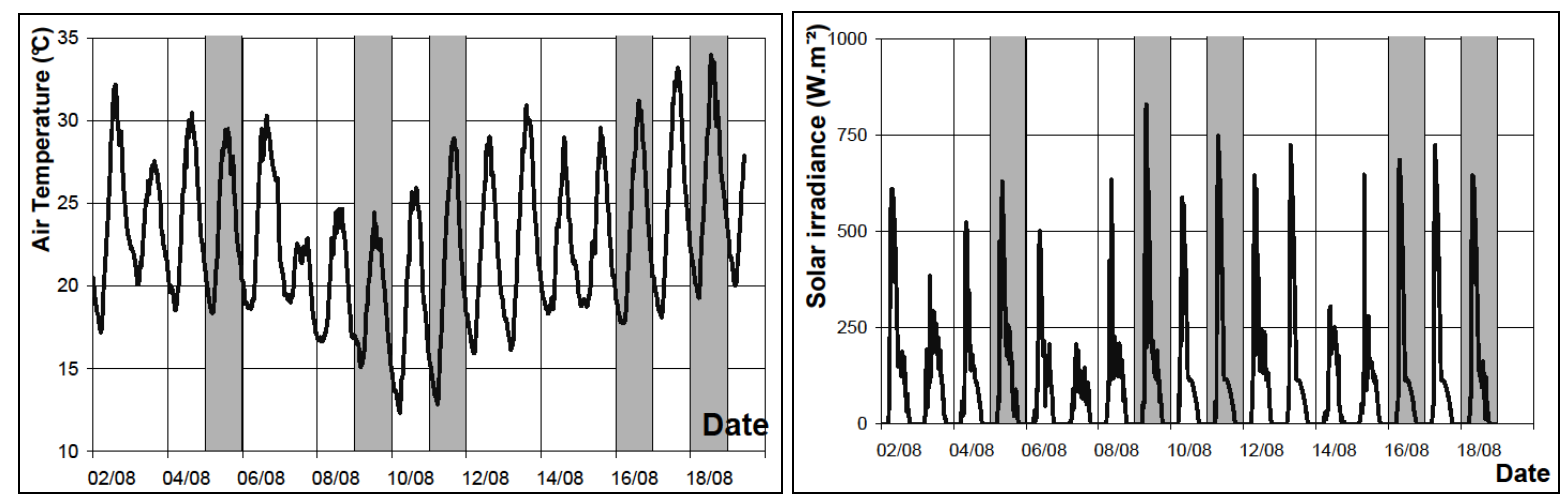

Fig. 9: Air temperature measurement (left) and solar irradiance on the eastern wall (right) from 01/08 to 19/08/2011. Measurements took place during time periods defined by coloured strips.

Five experimental sequences were defined, one for each hot wire position, and these will be detailed in the next part of this study. The corresponding weather conditions are indicated with coloured surfaces on Fig. 9. All sequences took place during warm weather and while solar irradiance levels were surpassing $570 \mathrm{~W} \cdot \mathrm{m}^{-2}$ (the value used to obtain CFD simulations). Even though the conditions were not identical for every sequence, they were studied in detail and found to be similar. Finally, all the five sequences were occurring under smooth wind conditions, that is to say wind speed measurements remained between 2 and $6 \mathrm{~m} \cdot \mathrm{s}^{-1}$ and wind direction remained mainly normal to the façade. 


\section{Results and discussion}

Two different results can be drawn from the experimental campaigns. First, measurements in the ventilated air gap can be used along with CFD results to describe the air flow behaviour. Second, temperature measurements can be analysed in order to be set against the one-dimensional heat transfer assumption. As both are related to the cladding temperature, this will be described first.

\subsection{Temperature distribution on the cladding}

IR measurements are taking place on the whole façade. For the sake of simplicity, only a few local measurements are presented below in Fig. 10; they have been selected to match the locations of the temperature sensors located on the rain-screen (see Table 3).

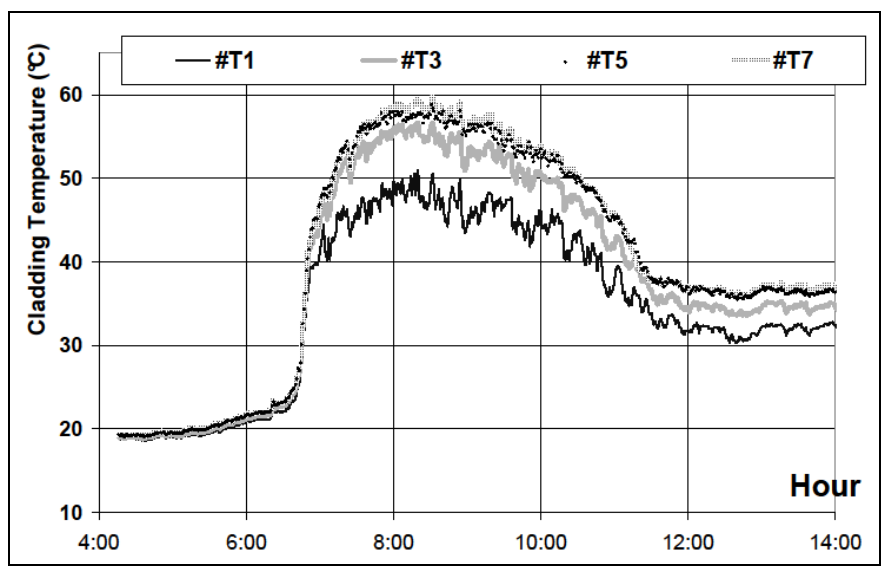

Fig. 10: Cladding temperature measured with the infrared camera on 16/08/2011 at 4 locations

These measurements clearly show that solar irradiance has a great influence on the surface temperature of the cladding. Based on preliminary experiments (Labat et al. 2011), the temperature distribution has been studied in detail and is resumed below with the following points:

- Before dawn, the cladding is $1{ }^{\circ} \mathrm{C}$ homogeneous over its entire surface and its temperature is very close to the air temperature.

- As soon as it is directly exposed to solar irradiation (at approximately $6 \mathrm{~h} 30$ during this experimental campaign, under a clear sky), an immediate temperature rise is measured over the entire height. Indeed, the surface temperature is not sensitive to thermal inertia.

- After a while, conductive and convective transfer is taking place and leads to a non uniform temperature distribution. The temperature at the bottom of the cladding is up to $10^{\circ} \mathrm{C}$ lower than the maximum values, which are measured at $\mathrm{z}=0.7$ between $8 \mathrm{~h}$ and $9 \mathrm{~h}$ and can surpass $60^{\circ} \mathrm{C}$. However, the large upper part (approximately $75 \%$ of the surface) is homogenous within $3^{\circ} \mathrm{C}$.

- From $9 \mathrm{~h}$ to $12 \mathrm{~h}$, direct solar irradiance decreases and so does the cladding's temperature. In the afternoon, the maximum temperature difference along the entire height remains between 4 and $5^{\circ} \mathrm{C}$ while the upper part is $2^{\circ} \mathrm{C}$ homogeneous.

\subsection{Air flow measurement in the ventilated air gap}

Vertical air gap velocity is plotted in Fig. 11 and in Fig. 12 for each anemometer location.

Measurements obtained at location \#V3 are added to allow comparison between sequences. 

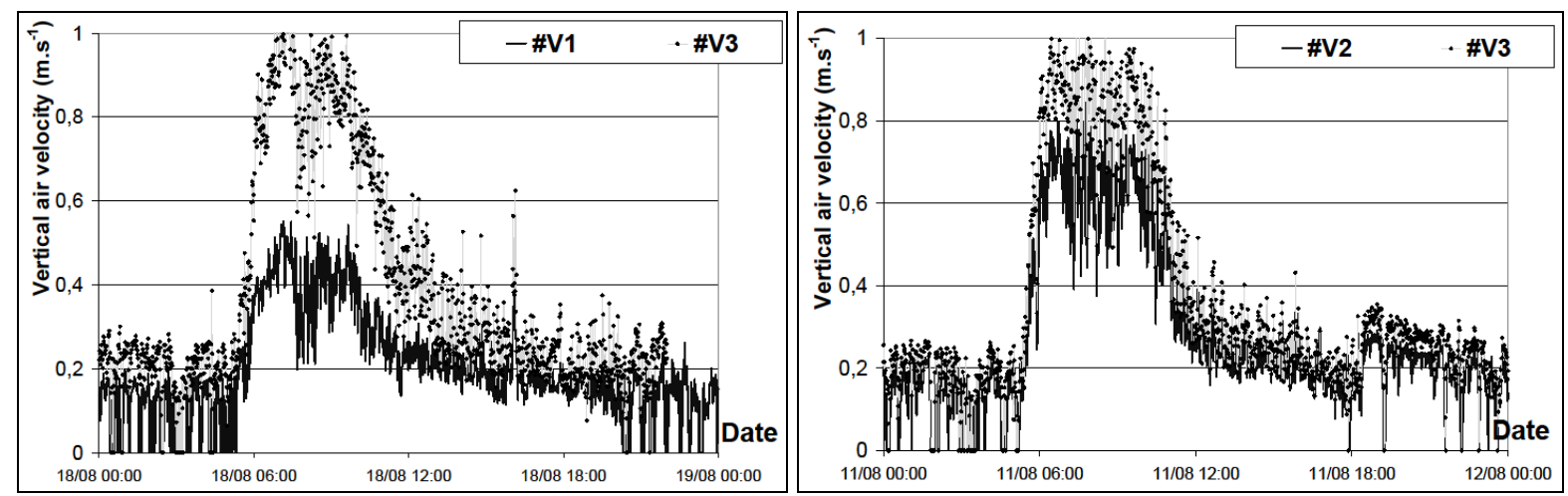

Fig. 11: Vertical air velocity comparison for anemometer locations \#V1 and \#V3 (left -18/08/2011) and \#V2 and \#V3 (right - 11/08/2011)
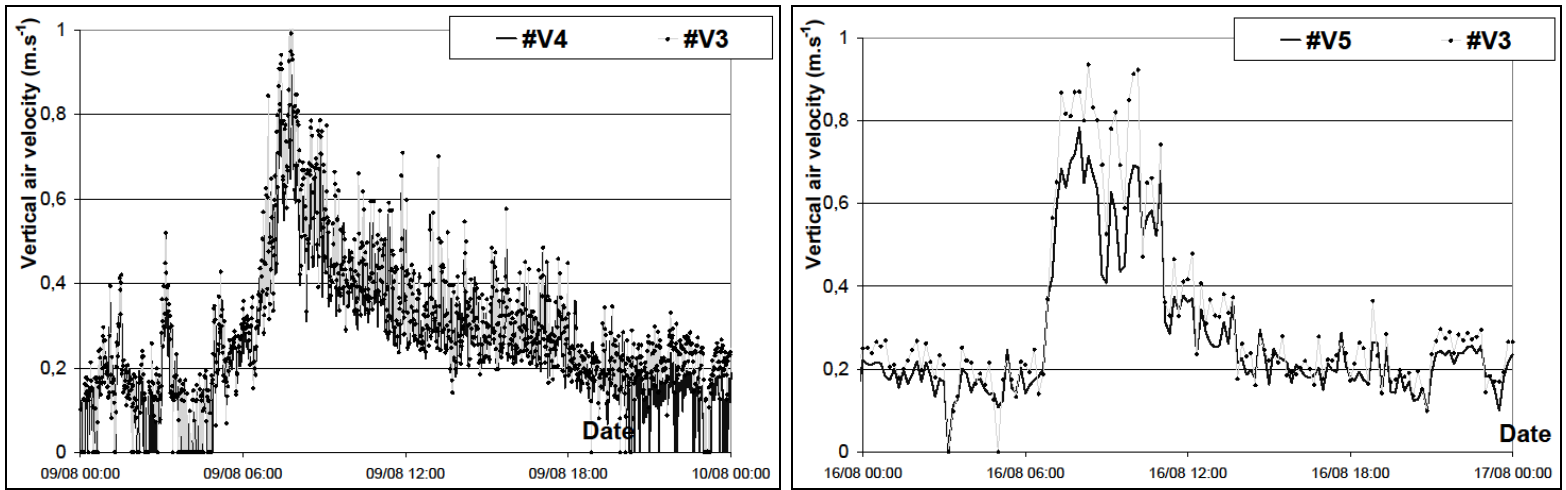

Fig. 12: Vertical air velocity comparison for anemometer locations \#V4 and \#V3 (left 09/08/2011) and \#V5 and \#V3 (right 16/08/2011 - acquisition frequency has been diminished to 1 recording every 10 minutes)

Several conclusions can be drawn from these measurements:

- The vertical velocity is not the same all day long and is clearly influenced by the cladding temperature.

- Magnitudes ranging from 0.1 to $0.3 \mathrm{~m} . \mathrm{s}^{-1}$ are measured during the night-time period. Maximum values are measured in the morning while the eastern cladding is exposed to solar irradiance and surpasses $0.9 \mathrm{~m} . \mathrm{s}^{-1}$ on $11 / 08$ and on $18 / 08$ (see Fig. 11).

- The air velocity at the bottom is not equal to the air velocity at mid-height (see Fig. 11). It is doubled from a relative height of $\mathrm{z}=0.25$ to $\mathrm{z}=0.55$ at $8 \mathrm{~h}$.

- Measurements obtained at locations \#V3 and \#V4 (see Fig. 12) are not significantly different, meaning possibly that no further secondary air flows are entering the ventilated air gap via openings between the boards at such heights. Another possibility is that one of the measurements could be biased, although there is no way of verifying such an assumption.

- Magnitude slightly decreases between \#V3 and \#V5 from 7h30 to 10h30 (see Fig. 12), that is to say when solar irradiance is greatest.

Such conclusions are consistent with CFD simulation results: the airflow rate seems to be moderately influenced by wind whenever no direct solar irradiance is occurring. This concords with the findings of Olof Hägerstedt (2011) and Piot (2009) as they both opted for using a constant airflow rate without taking into account wind effect. When direct solar irradiance is occurring however, the air flow is greatly increased (its velocity can be multiplied by 4 or 5) and reaches values predicted with the CFD 
simulation in 3.2. These observations allow concluding that the buoyancy effect is strongly influencing the air gap behaviour and has to be taken into account.

\subsection{Conceivable simplification when considering the building scale}

From a general point of view, one dimensional models are widely used to describe heat transfer in walls at the building scale. In this case some average values should be used and they are presented in the following.

Several rain-screen temperature measurements are presented in Fig. 13. In order to facilitate their comparison with measurements on the cladding (Fig. 10), the same temperature scale has been used to plot the measurements obtained at the same heights.

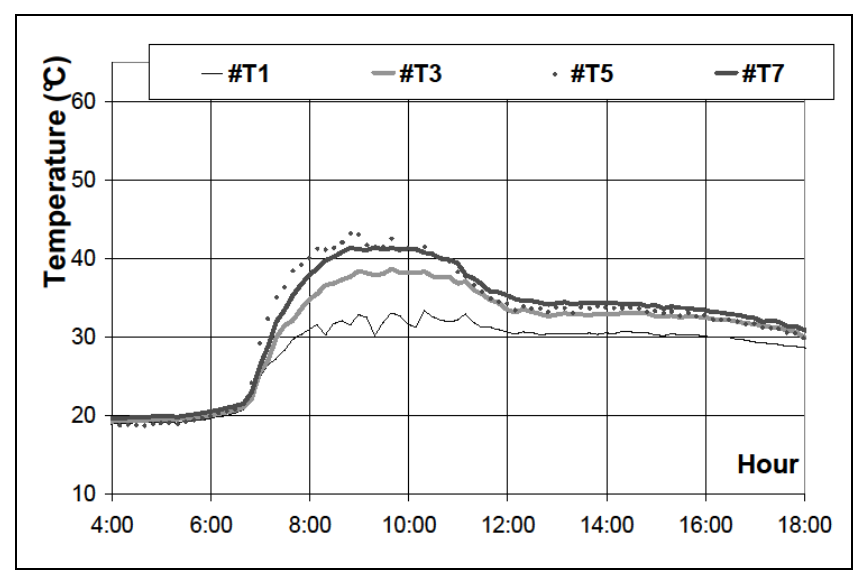

Fig. 13 : Rain-screen temperature measured with the thermocouples on 16/08/2011 at 4 locations

The general evolution of the rain-screen temperature is similar to that observed with the IR camera over the cladding. However, the ventilated air gap efficiently reduces overheating due to direct solar irradiance. Indeed, the maximum rain-screen temperature does not exceed $45^{\circ} \mathrm{C}$, which is far lower than the highest temperature measured on the cladding the same day $\left(\right.$ almost $\left.60^{\circ} \mathrm{C}\right)$.

In order to give preliminary elements on modelling heat transfer through the cladding, the rain-screen temperature distribution was studied in great detail and set against the one dimensional assumption. Indeed, such an assumption has been used in recent studies, such as in Patania et al. (2010) to estimate the energy savings with a ventilated façade, as it is a very convenient means of modelling heat transfer quickly. In our case, temperature distribution was computed during three periods:

- During the night, from $22 \mathrm{~h}$ to $05 \mathrm{~h}$

- When direct solar irradiance is occurring, from $06 \mathrm{~h}$ to $11 \mathrm{~h}$

- When diffuse solar irradiance is occurring, from $12 \mathrm{~h}$ to $18 \mathrm{~h}$

Distributions are compared to intervals defined as follow: [Tavg $-\sigma$; Tavg $+\sigma]$ where Tavg stands as the average temperature of the rain-screen and $\sigma$ is a constant value. A partial distribution has also been computed and corresponds to the indoor panel, so temperatures measured below the floor (from \#T1 to \#T2 in Table 3) or above the ceiling (from \#T7 to \#T8) are not considered. Results are presented in Table 4.

Table 4: Percentages of rain-screen temperature distribution included in given ranges

\begin{tabular}{lllll}
\hline$\sigma$ & $\pm 0,5\left({ }^{\circ} \mathrm{C}\right)$ & & $\pm 1\left({ }^{\circ} \mathrm{C}\right)$ & \\
\hline Temperature Distribution & Global & Partial & Global & Partial \\
\hline
\end{tabular}




\begin{tabular}{llllll}
\hline \multirow{2}{*}{ Period } & Direct irradiance & $17 \%$ & $72 \%$ & $35 \%$ & $92 \%$ \\
& Diffuse irradiance & $51 \%$ & $91 \%$ & $83 \%$ & $100 \%$ \\
& Night time & $74 \%$ & $92 \%$ & $95 \%$ & $100 \%$ \\
\hline
\end{tabular}

The lowest values are computed along the entire height when direct solar irradiance is occurring. This means that the distribution is widespread and asymmetrical, so using an average temperature is not representative.

Partial distributions are clearly more homogeneous than global distributions: $92 \%$ is $\pm 1{ }^{\circ} \mathrm{C}$ homogeneous in rough conditions, $\pm 0.5^{\circ} \mathrm{C}$ homogeneous otherwise. This means that somehow, the rain-screen temperature distribution is widely spread because of the ventilated air gap. But in our particular case, the greatest deviations are located at the roof and ceiling levels. Both locations are already bound to behave specifically (the so called thermal-bridges).

These experimental results show that, when no precise assessment of wall performance is needed, the average behaviour of the ventilated cladding can be considered. It can be evaluated from heat transfer taking place at mid-height of the wall. This approach would be appropriate for estimating the global energy performance of such a cladding, but gives no insight into the behaviour of the ventilated gap.

\subsection{Estimation of the average airflow rate in the ventilated air gap at different heights}

Based on the measurements described in section 5.2 and on general results presented in Sanjuan et al. (2011), a general correlation has been developed. It aims at estimating the average airflow rate in the ventilated air gap under dynamic temperature and irradiance conditions. In addition, it has to include the experimentally confirmed influence of airflow rates entering the air gap through the numerous openings. The correlation relies on the following assumptions:

- Measurements achieved with thermo-anemometers are representative of the average airflow rate and temperature for a given relative height.

- At a relative height $\mathrm{z}_{\mathrm{NA}}$ there is no horizontal airflow rates $\mathrm{q}_{\mathrm{x}}$. Outdoor air is coming in the air gap through the boards underneath $\mathrm{z}_{\mathrm{NA}}$, out of the air gap above. As a consequence, the vertical airflow rate $\mathrm{q}_{\mathrm{Z}}$ is the highest at $\mathrm{z}_{\mathrm{NA}}$.

- Measurements achieved at location \#V3 during the whole experimental campaign are set against measured temperature difference $\Delta \mathrm{T}_{\mathrm{Z}=\mathrm{ZNA}}$ between outdoor air and the air gap at $\mathrm{z}_{\mathrm{NA}}$ in Fig. 14. This dependence is modelled with a linear function. The second equation in (2) shows such a function with the intercept volume $\mathrm{q}_{0}\left(\mathrm{~m}^{3} \cdot \mathrm{h}^{-1}\right)$ and slope $\mathrm{k}\left(\mathrm{m}^{3} \cdot \mathrm{h}^{-1} \cdot \mathrm{K}^{-1}\right)$.

- The vertical airflow rate variation $\mathrm{dq}_{\mathrm{z}}$ along the height results from the horizontal air flow rates only $\mathrm{q}_{\mathrm{X}}$.

- The relative contribution of the horizontal airflow rates is a linear function of relative height (see Fig. 14) depending on a parameter $\gamma$.

- There is a non-zero airflow rate at the lowest $(\mathrm{z}=0)$ and highest $(\mathrm{z}=1)$ edges of the ventilated air gap, modelled with parameter $\delta$, as presented in the equation (2).

- Due to the geometry of the cladding boards, vertical airflow rate is not symmetrical. For this reason, all parameters related to the lower part $\left(\mathrm{z}<\mathrm{z}_{\mathrm{NA}}\right)$ will be written with the subscript ${ }_{\mathrm{LO}}$ while those related to the upper part $\left(\mathrm{z}>\mathrm{z}_{\mathrm{NA}}\right)$ will be written with the subscript $\mathrm{UP}$. 

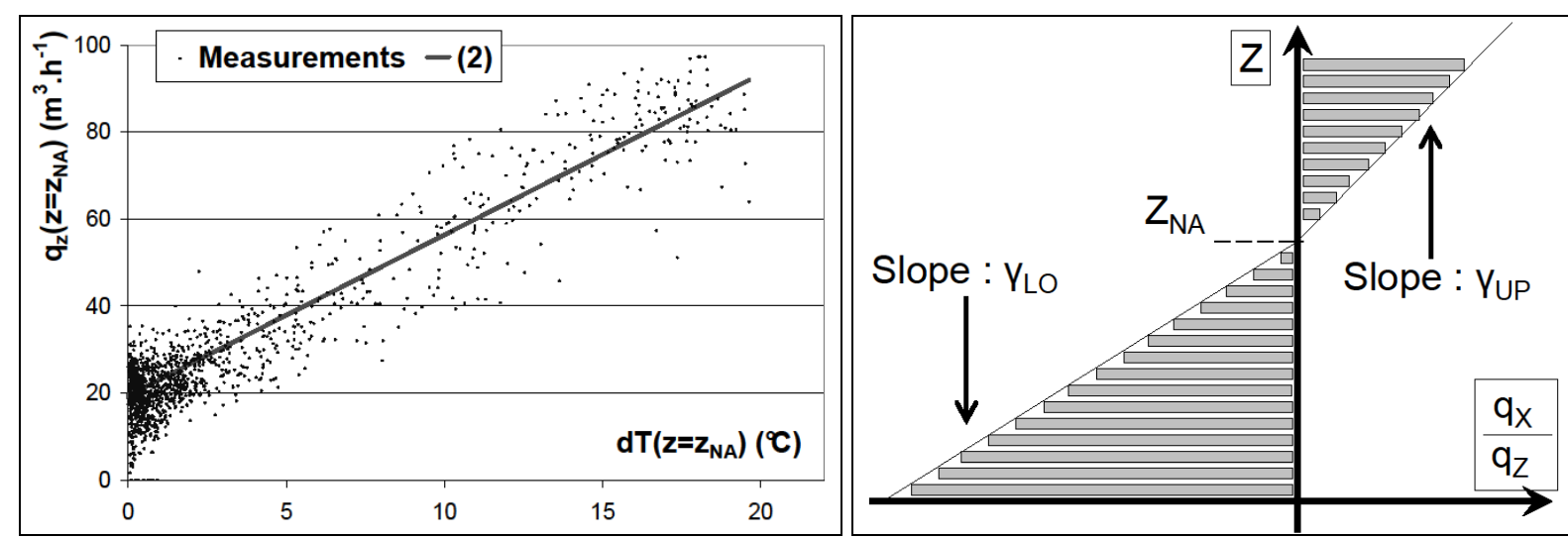

Fig. 14 : Comparison of measured airflow rate at middle height with (3) (left) and assumption on the relative contribution of horizontal airflow rates depending on the relative height (right)

Based on these assumptions, the boundary conditions can be defined as follows:

$$
\begin{aligned}
& q_{Z}(z=0)=\delta_{L O} \cdot\left(q_{0}+k \cdot \Delta T_{z=z_{N A}}\right) \\
& q_{Z}\left(z=z_{N A}\right)=q_{0}+k \cdot \Delta T_{z=z_{N A}} \\
& q_{Z}(z=1)=\delta_{U P} \cdot\left(q_{0}+k \cdot \Delta T_{z=z_{N A}}\right)
\end{aligned}
$$

The differential equation (3) represents the general behaviour of the lower part of the ventilated air gap. Its general solution is presented in (4). It is identical when considering the upper part, except for $\gamma_{\mathrm{LO}}$ which has to be replaced with $\gamma_{\mathrm{UP}}$.

$$
\begin{aligned}
& \frac{d q_{Z}(z)}{q_{Z}(z)}=\gamma_{L O} \cdot\left(1-\frac{z}{z_{N A}}\right) \cdot d z \\
& q_{Z}\left(z<z_{N A}\right)=A_{1} \cdot e^{\gamma_{L O}\left(z-\frac{z^{2}}{2 \cdot z_{N A}}\right)} \\
& q_{Z}\left(z>z_{N A}\right)=A_{2} \cdot e^{\gamma_{U P}\left(z-\frac{z^{2}}{2 \cdot z_{N A}}\right)}
\end{aligned}
$$

$\gamma_{\mathrm{LO}}$ can be expressed as a function of $\mathrm{z}_{\mathrm{NA}}$ and $\delta_{\mathrm{LO}}$. To do so, (3) is integrated between 0 and $\mathrm{z}_{\mathrm{NA}}$, which gives (5).

$$
\left[\ln \left(q_{Z}(z)\right)\right]_{0}^{z_{N A}}=\gamma_{L O} \cdot\left[z-\frac{z^{2}}{2 \cdot z_{N A}}\right]_{0}^{z_{N A}}
$$

Equation (5) is solved using boundary conditions presented in (2). The same approach can be used with $\gamma_{\mathrm{UP}}$ and the final expressions of $\gamma_{\mathrm{LO}}$ and $\gamma_{\mathrm{UP}}$ are presented in (6) below. 


$$
\begin{aligned}
& \gamma_{L O}=-\frac{2}{z_{N A}} \cdot \ln \left(\delta_{L O}\right) \\
& \gamma_{U P}=\left(1-\frac{1}{2 \cdot z_{N A}}-\frac{z_{N A}}{2}\right)^{-1} \cdot \ln \left(\delta_{U P}\right)
\end{aligned}
$$

Constants $\mathrm{A}_{1}, \mathrm{~A}_{2}$ are determined by using the boundary conditions presented in (2).

$$
\begin{aligned}
& q_{Z}(z=0)=\delta_{L O} \cdot\left(q_{0}+k \cdot \Delta T_{z=z_{N A}}\right)=A_{1} \\
& q_{Z}\left(z=z_{N A}\right)=q_{0}+k \cdot \Delta T_{z=z_{N A}}=A_{1} \cdot e^{\frac{\gamma_{L O} z_{N A}}{2}}=A_{2} \cdot e^{\frac{\gamma_{U P} z_{N A}}{2}} \\
& q_{Z}(z=1)=\delta_{U P} \cdot\left(q_{0}+k \cdot \Delta T_{z=z_{N A}}\right)=A_{2} \cdot e^{\gamma_{U P}\left(1-\frac{1}{2 \cdot z_{N A}}\right)}
\end{aligned}
$$

The solution is given in (8) for both the lower and upper part of the ventilated air gap.

$$
\begin{aligned}
& q_{Z}\left(z<z_{N A}\right)=\delta_{L O}\left(q_{0}+k \cdot \Delta T_{z=z_{N A}}\right) e^{\gamma_{L O}\left(z-\frac{z^{2}}{2 \cdot z_{N A}}\right)} \\
& q_{Z}\left(z>z_{N A}\right)=\delta_{U P}\left(q_{0}+k \cdot \Delta T_{z=z_{N A}}\right) e^{-\gamma_{U P} \cdot\left(1-\frac{1}{2 \cdot z_{N A}}\right)} \cdot e^{\gamma_{U P} \cdot\left(z-\frac{z^{2}}{2 \cdot z_{N A}}\right)}
\end{aligned}
$$

In our case, the five coefficients $\left(\mathrm{z}_{\mathrm{NA}} ; \mathrm{q}_{0} ; \mathrm{k} ; \delta_{\mathrm{LO}} ; \delta_{\mathrm{UP}}\right)$ have been computed using a least square fitting method. . The correlation represents the air flow rate for a $1 \mathrm{~m}$ wide air cavity (cross section: $0.027 * 1 \mathrm{~m}^{2}$ ). Values are presented in Table 5 and the results of the correlation (8) are plotted against measurements taken at locations \#V1, \#V3 and \#V5 in Fig. 15.

Table 5: Coefficients calculated using least square fitting

\begin{tabular}{lllll}
\hline $\mathrm{Z}_{\mathrm{NA}}(-)$ & $\mathrm{q}_{0}\left(\mathrm{~m}^{3} \cdot \mathrm{h}^{-1}\right)$ & $\mathrm{k}\left(\mathrm{m}^{3} \cdot \mathrm{h}^{-1} \cdot \mathrm{K}^{-1}\right)$ & $\delta_{\mathrm{LO}}(-)$ & $\delta_{\mathrm{UP}}(-)$ \\
\hline 0.57 & 19.44 & 3.694 & 0.20 & 0.70 \\
\hline
\end{tabular}
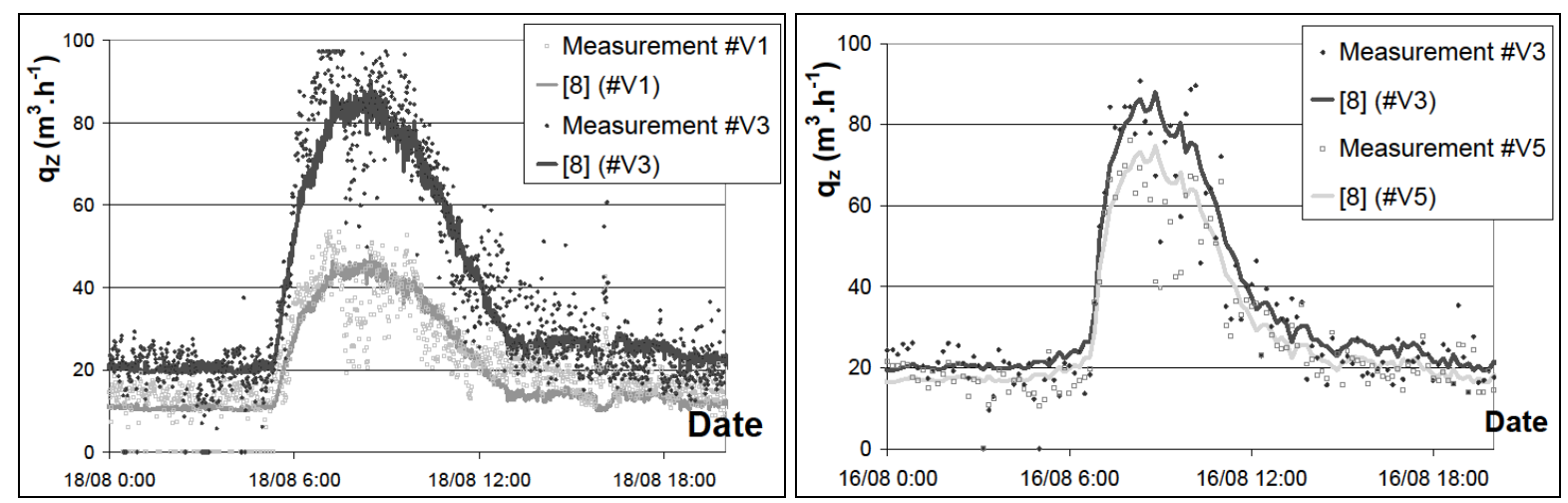

Fig. 15 : Comparison of (8) with measurements recorded on 18/08/2011 (left) and 16/08/2011 (right)

Correlation (8) efficiently represents the impact of solar irradiance on the ventilated air gap behaviour. The assumed impact of horizontal air flows is found to be correctly modelled. Moreover, 
correlation (8) is based on fundamental observations and should easily be adapted to different claddings with open joints.

\subsection{Limitations and outlook}

In this work heat and air transfers around a ventilated cladding were numerically and experimentally investigated. Based on these observations a model to calculate the air flow rate behind the cladding was proposed as a function of cladding overheating. The model was validated against measurements of air velocity. The values are scattered, which can not be attributed to thermal effects only as shown in Fig. 14. The scattering is probably due to the impact of wind, and induced turbulences. Although wind may have an impact on the vertical air flow rate, its influence is less significant for the mean values than the effect of buoyancy (see Fig 14). Air velocity measurements in the air gap are validating this statement for low and moderate wind velocities $\left(<6 \mathrm{~m} \cdot \mathrm{s}^{-1}\right)$ and for wide range of wind incidence. Observed low wind influence is not surprising as measurements took place far away from the building edges and as each ventilated cavity is independent from others. However, applying correlation (8) under low direct solar irradiance would have result in an almost constant airflow rate and may have lacked of accuracy compared to other correlations (Gudum 2003). It should also be mentioned that correlation (5) has been validated against measurements located between relative heights $\mathrm{z}=0.23$ and $\mathrm{z}=0.91$. Its validity for upper and lower parts of the air cavity cannot be verified.

The use of CFD simulations in the present work was prompted by the need of understanding the general air flow behaviour. Since such detailed tools are not well adapted to whole building simulations, and because this simulation refers to a non-wind case, while measurements are occurring under low wind velocities, no further comparison between CFD results and measurements was developed.

The proposed correlation can be directly integrated in a model using temperatures as state variables, not including pressure network. A more precise representation could be achieved by including pressure calculations using for example a zonal model, as proposed in Kuznik et al. (2011). The ventilated air gap could then be cut into strips, so that horizontal and vertical airflows can be assessed. The cladding behaviour could be compared to other geometries and the boundary conditions on the insulated part of the wall would be estimated in detail. Similar outlook was also suggested in Zerihun et al. (2011) to validate HAM models.

\section{Conclusions}

Experiments waere carried out on an open-jointed cladding, exposed to direct solar irradiance during the summer. It was set up in order to learn more about the heat transfer taking place all around the cladding.

The ventilated air gap was investigated numerically with buoyancy as the main driving force. It was revealed that the air velocity is greatly influenced by secondary air flows coming in through the numerous openings. When comparing the behaviour of the ventilated air gap with temperature measurements obtained on the outdoor side of the cladding, it became apparent that the air flow magnitude is strongly influenced by solar irradiance: it is four times higher when compared to nighttime periods. As a consequence, the vertical velocity is not constant along the entire height and depends on solar irradiance. This statement was experimentally verified by setting hot wire anemometers in the ventilated air gap during the summer time. 
The temperature distribution on the wall surface behind the cladding was also studied in detail. Even though high deviations were measured at the inlet and outlet, the insulated wall was $\pm 1{ }^{\circ} \mathrm{C}$ homogeneous in rough cases. When no precise assessment of wall performance is needed, a onedimensional model representing the average behaviour of the ventilated cladding should be appropriate for estimating its energy performance.

For more detailed studies of airflow behaviour, including two-dimensional phenomena, a correlation to assess air flow rate has been proposed. The correlation is based upon experimental conclusions and uses temperature differences. It efficiently represents the average airflow in the cavity at different heights for various irradiance and temperature conditions. As the proposed approach relies on general observations, it is anticipated that it will be suited for different ventilated cavities with numerous openings under direct solar radiation. In addition, an interesting perspective of the proposed correlation lies in its integration into whole-building model to improve the assessment of energy performance of walls with open-jointed ventilated claddings.

\section{Acknowledgements}

The authors would like to thank ADEME (French Environment and Energy Management Agency, OPTI-MOB project, $\mathrm{n}^{\circ}$ 0704C0099) for financial support.

\section{References}

Bazilian M.D., Kamalanathan H., Prasad D.K., 2002, Thermographic analysis of a building integrated photovoltaic system, Renewable Energy 26 p.449-461

Buchlin J.M., 2010, Convective Heat Transfer and Infrared Thermography (IRTh), Journal of Applied Fluid Mechanics, vol. 3, $\mathrm{n}^{\circ}$ 1, p.55-62

Dactu S., Ibos L., Candau Y., Matteï S., 2005, Improvement of building wall surface temperature measurements by infrared thermography, Infrared Physics \& Technology 46, p.451-467

Fossa M., Ménézo C., Leonard E., 2008, Experimental natural convection on vertical surfaces for building integrated photovoltaic (BiPV) applications, Experimental Thermal and Fluid Science 32 980-990

Gan G., 2009, Numerical determination of adequate air gaps for building-integrated photovoltaics, Solar Energy 83 1253-1273

Gudum C., 2003, Moisture Transport and convection in building envelopes, Ventilation in light weight outer walls, Doctoral Thesis ISBN 87-7877-107-2, Technical University of Danemark, Danemark

Hensen J., Bartak M., Drkal F., 2002, Modelling and simulation of a double-skin façade system, American Society of Heating, Refrigerating, and Air-Conditioning Engineers, Vol 108, Part 2

Holm A., 2009, Whole building heat, air, moisture response: applications, Final Report IEA, EXCO ECBCS Annex 41, subtask 4, ACCO, Leuven,

Korukçu M., Kilic M., 2009, The usage of IR thermography for the temperature measurements inside an automobile cabin, International Communications in Heat and Mass Transfer 36, p.872-877

Kuznik F., Catalina T., Gauzere L., Woloszyn M., Roux J.J., 2011, Numerical modelling of combined heat transfers in a double skin façade - Full scale laboratory experiment validation, Applied Thermal Engineering 31, 3043-3054

Labat M., Garnier G., Woloszyn M., Roux J.J., 2011, Infrared measurements on a ventilated cladding for assessing its surface temperature and heat transfer calculation through the insulated part of the envelope using a simulation tool, $9^{\text {th }}$ Nordic Symposium on Building Physics, Vol1, 315-322

Nore K., 2009, Hygrothermal performances of ventilated wooden cladding, Doctoral thesis, Norwegian University of Science and Technology, Trondheim, Norway 
Nore K., Blocken B., Thue J. V., 2010, On CFD simulation of wind-induced airflow in narrow ventilated facade cavities: Coupled and decoupled simulations and modelling limitations, Building and Environment 45, 1834 1846

Olof Hägerstedt S., Harderup L.E., 2011, Comparison of measured and calculated temperature and relative humidity with varied and constant air flow in the façade air gap, $9^{\text {th }}$ Nordic Symposium on Building Physics, Vol1, 147-154

Patania F., Gagliano A., Nocera F., Ferlito A., Galesi A., 2010, Thermofluid-dynamic analysis of ventilated facades, Energy and Buildings 42, 1148-1155

Piot, 2009, Hygrothermique du bâtiment : expérimentation sur une maison à ossature bois en conditions climatiques naturelles et modélisation numérique, Doctoral thesis, INSA-Lyon, France

Piot A, Woloszyn M, Brau J, Abele C., 2011, Experimental wooden frame house for the validation of whole building heat and moisture transfer numerical models, Energy and Buildings 43, 1322-1328

Sanjuan C., Suàrez M.J., Blanco E., del Rosario Heras M., 2011, Development and experimental validation of a simulation model for open joint ventilated façades, Energy and Buildings 43, 3446-3456

Yilmaz T., Fraser S.M., 2007, Turbulent natural convection in a vertical parallel plate channel with asymmetric heating, International Journal of Heat and Mass Transfer 50, 2612-2623

Zerihun T., Langmans J., Roels S., 2011, Experimental data set for validation of heat, air and moisture transport models of building envelopes, Building and Environment 46, 1038-1046 